Supporting Information

\title{
Room-temperature Chemical Welding and Sintering of Metal Nanostructures by Capillary Condensation
}

\author{
Sung-Soo Yoon and Dahl-Young Khang* \\ Department of Materials Science and Engineering, Yonsei Univeristy
}

*Author to whom correspondence should be addressed. 


\section{(1) Materials}

Metal nanostructures were purchased as follows: Ag nanowires $(\sim 30 \mathrm{~nm}$ in diameter and $\sim 30 \mu \mathrm{m}$ in length, Nanopyxis), Ag nanoparticles (ANP), $\mathrm{Cu}, \mathrm{Fe}, \mathrm{Co}$, and $\mathrm{Ni}$ nanoparticles (CNvision). All the nanoparticles have nominal diameter of 50nm. Some of these products were in solution form, with minimal amount of additives by special request. Products in dry powder state were dispersed in ethanol/water (1:1 in vol.), using $2 \mathrm{wt} \%$ of polyvinylpyrrolidone (PVP, Aldrich) as surfactant. Hydrogen peroxide (OCI Chemicals) was used without any further purification or treatment. Polydimethylsiloxane (PDMS, Sylgard 184, Dow) was prepared by mixing base resin to curing agent in 10:1 weight ratio. Polyethyleneterephthalate (PET) substrate was cleaned in ethanol and DI water before usage.

\section{(2) Chemical welding and sintering}

Layers of metal nanostructures were prepared on substrates, such as PET, Si or glass by spin-coating or spraying. Then the samples were simply hung facing downward on a beaker containing hydrogen peroxide for specific time duration at room temperature. For easily oxidizable metals, such as $\mathrm{Cu}, \mathrm{Fe}, \mathrm{Co}$, and $\mathrm{Ni}$, it has been found that surface oxide layer should be removed before the welding/sintering by $\mathrm{H}_{2} \mathrm{O}_{2}$ vapor. Addition of small amount of hydrazine hydrate $\left(\mathrm{N}_{2} \mathrm{H}_{4} \cdot \mathrm{H}_{2} \mathrm{O}\right)$ into the nanoparticle solutions has been found to be enough for the purpose. To expedite the welding/sintering process, the beaker containing hydrogen peroxide was mounted on a hot plate heated to $70^{\circ} \mathrm{C}$.

\section{(3) Bendable and stretchable AgNW networks}

For bending test, AgNWs were spun on flexible PET substrate. After treating the sample with hydrogen peroxide vapors for chemical welding, the bending tests were carried out on a home-made stage with 2-point I-V measurements. For a good electrical contact with probe tips, patterned electrodes of $\mathrm{Ti}(10 \mathrm{~nm}) / \mathrm{Au}(100 \mathrm{~nm})$ were deposited on sample surface by ebeam evaporation using shadow mask. The electrodes were in $3 \mathrm{~mm}^{*} 20 \mathrm{~mm}\left(\mathrm{~L}^{*} \mathrm{~W}\right)$ in size and $10 \mathrm{~mm}$ spaced apart.

For the fabrication of stretchable AgNWs network, the AgNWs layer was firstly prepared on glass substrate by spin or spray coating methods. The quantity or thickness of AgNWs was controlled by solution concentration, spin speed and spray volume. After the roomtemperature chemical welding, PDMS prepolymer was poured onto the sample and cured at 
$60^{\circ} \mathrm{C}$ for an hour. Detaching the cured PDMS off the substrate has finally yielded partially embedded, welded network of AgNWs. For the easy and clean release of the sample off glass substrate, a sacrificial PMMA ( 500nm) layer was formed on the substrate before AgNWs layer formation. The exposed surface of AgNWs network can make it easy to form direct electrical contact with other surfaces in many practical device applications.

\section{(4) Stretchable heater device}

A latex glove was cut into small piece $(\sim 2 \mathrm{~cm} * 2 \mathrm{~cm})$ and cleaned in methanol with sonication for 3min. After $\mathrm{N}_{2}$ blow-drying, the piece was attached to a cured slab of PDMS using 3M bi-facial tape. AgNWs network was formed on the latex piece by spin-coating (3000rpm, 30sec). Then, AgNWs network on latex piece was chemically welded through $\mathrm{H}_{2} \mathrm{O}_{2}$ vapor exposure for $15 \mathrm{~min}$. The electrode $(\mathrm{Ti} / \mathrm{Ag}, 5 \mathrm{~nm} / 50 \mathrm{~nm})$ was deposited on the sample using e-beam evaporator. For stable electrical contact that can survive the mechanical stress of alligator clip of DC power supply, $\mathrm{Cu}$ tape was attached to the Ti/Ag electrode and the gap between them was completely filled with silver paste. Then, the sample was coated with PDMS by spin-coating (100rpm, 30sec) and cured at $65^{\circ} \mathrm{C}$ for $3 \mathrm{hrs}$. Finally, the PDMSAgNWs-latex sample was attached to another latex glove using another layer of PDMS as an adhesive, and fully cured at $65^{\circ} \mathrm{C}$ for $5 \mathrm{hrs}$.

\section{(5) Characterization}

The measurements of electrical resistance, before/after the process, were used to verify the chemical welding/sintering indirectly. For uniform layers of metal nanostructures on hard substrates, four-point probe (AiT, CMT-SR1000N) technique was used to directly measure the sheet resistance. Otherwise, simple 2-point I-V measurements (Semiconductor analyzer, HP-4156A) were used to get the resistance. Either patterned Ti/Au electrodes (for bending tests) or eutectic GaIn (Aldrich) electrodes (for stretching tests) were used for the I-V measurement. Then the sheet resistance value was extracted using the conversion formulae. This conversion has led to $\sim 10 \%$ higher sheet resistance values, compared to those from direct 4-point probe measurements (Supplementary Fig. S14). Optical measurements such as transmittance and haze were carried out by JCH-200S (J\&C Tech.) by the courtesy of LG Display Co. Ltd. For sample imaging, SEM (JEOL, 7001F), TEM (FEI, Technai G2 F30STwin), and AFM (MFP-3D, Asylum) were used. DC power supply (SMU 2400, Keithley) 
was used to apply bias voltage for stretchable heater devices. The temperature of those heaters was measured by IR camera (R300W2 R17, Nec Avio). 


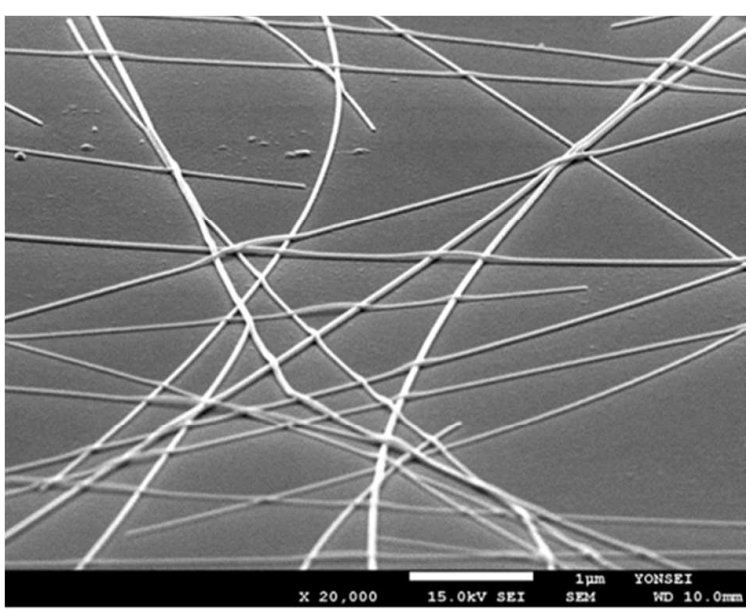

(a)

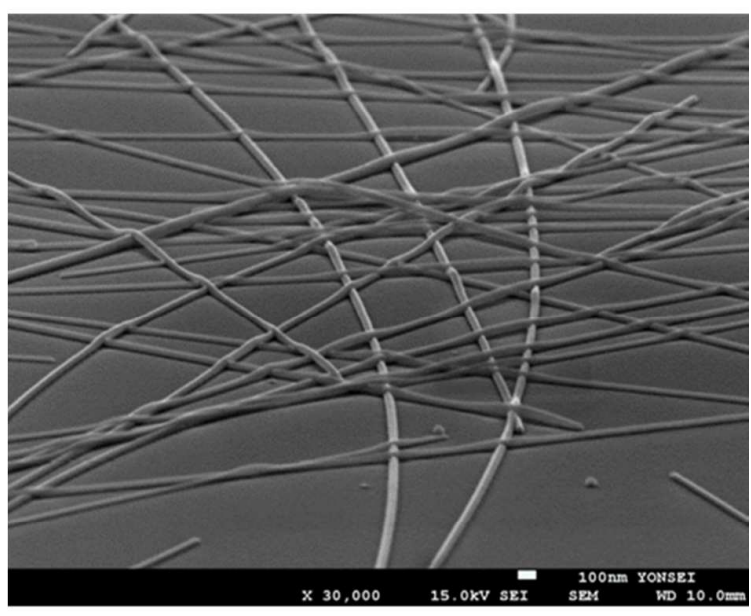

(b)

Figure S1. Low-magnification large-area SEM images of AgNWs network, before (a) and after (b) the chemical welding. 

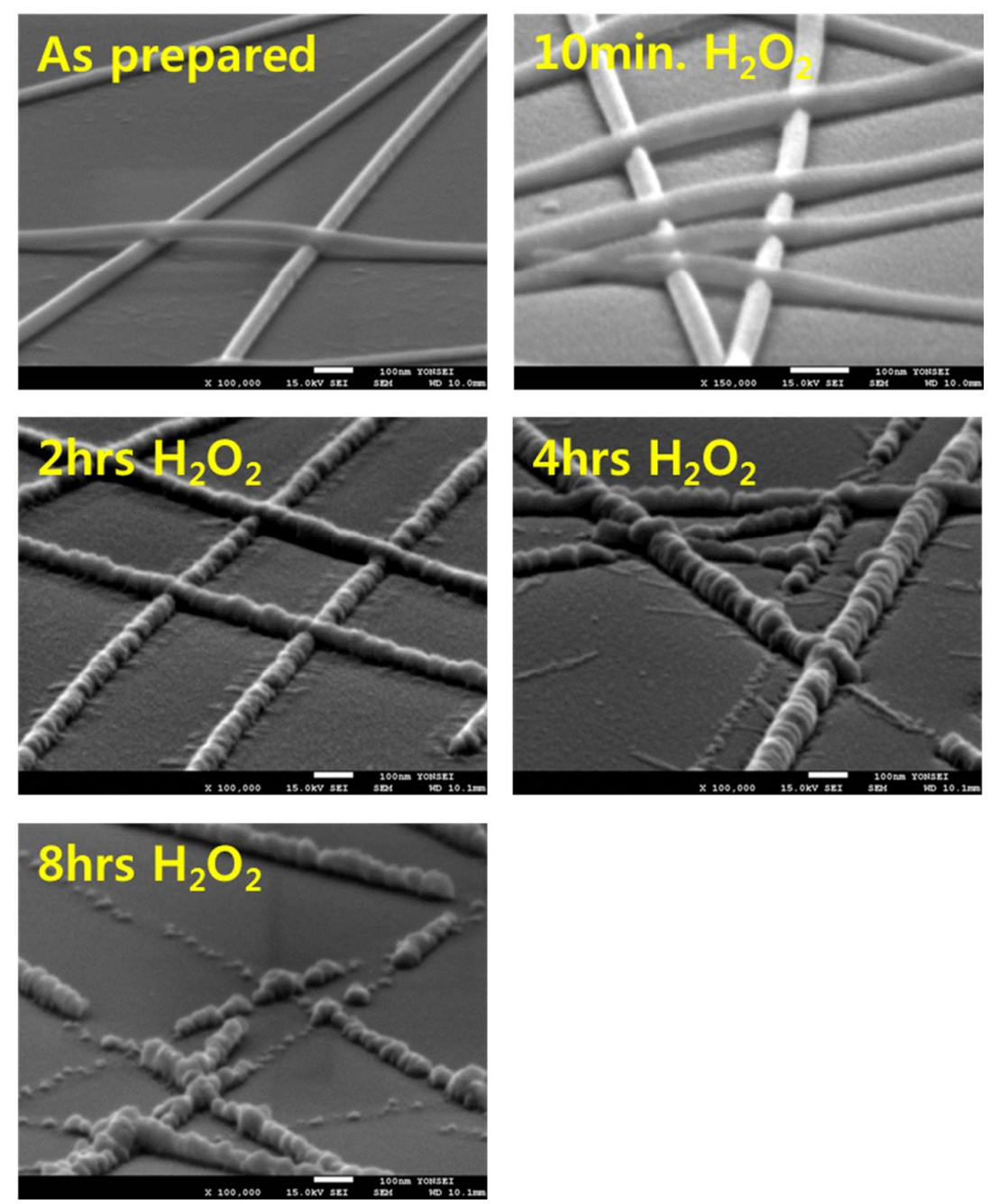

Figure S2. Morphology change of AgNWs network upon prolonged exposure to $\mathrm{H}_{2} \mathrm{O}_{2}$ vapor at room temperature. As the treatment time increases, the surface of AgNWs becomes wobble and nanowires are broken into fragments. Condensation of $\mathrm{H}_{2} \mathrm{O}_{2}$ vapor onto the NWs surface, as well as the junctions, and ensuing dissolution are responsible for the observed results. This morphological change accompanies steep increase in electrical resistance, as shown in Fig. 2a of Main Text. 

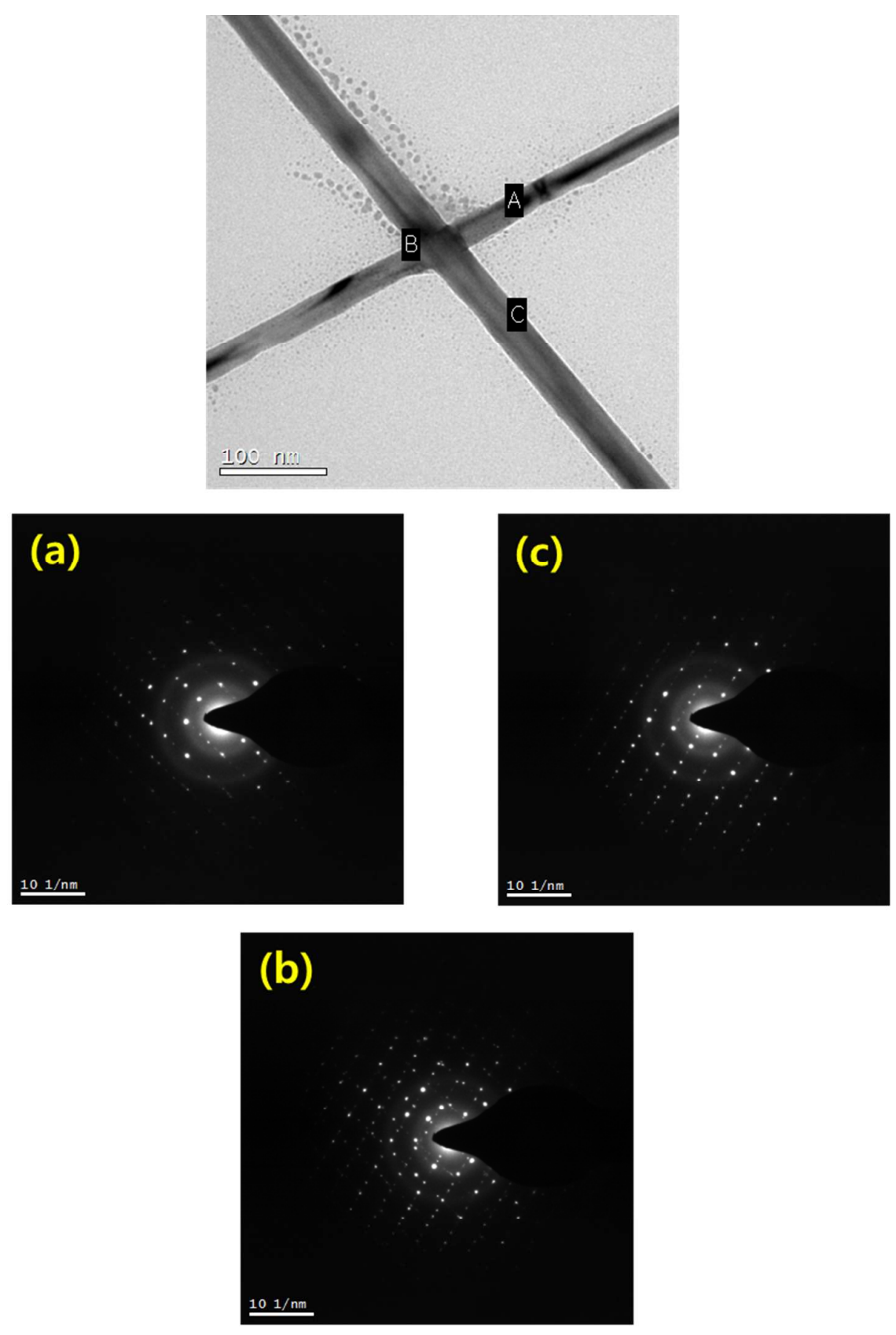

Figure S3. TEM analysis of chemically welded AgNWs network. (Top) HR-TEM image of the welded junction. $(\mathrm{a} \sim \mathrm{c})$ SAED patterns from various locations that are labeled in the top image. The SAED pattern on the welded junction (b) is quite similar to the simple overlap of SAED patterns from each nanowire (a and $\mathrm{c}$ ). The nanowires maintain their own crystalline directions even after the chemical welding, which means the chemical welding is a very localized and surface process, without involving any change in the bulk of nanowires. 


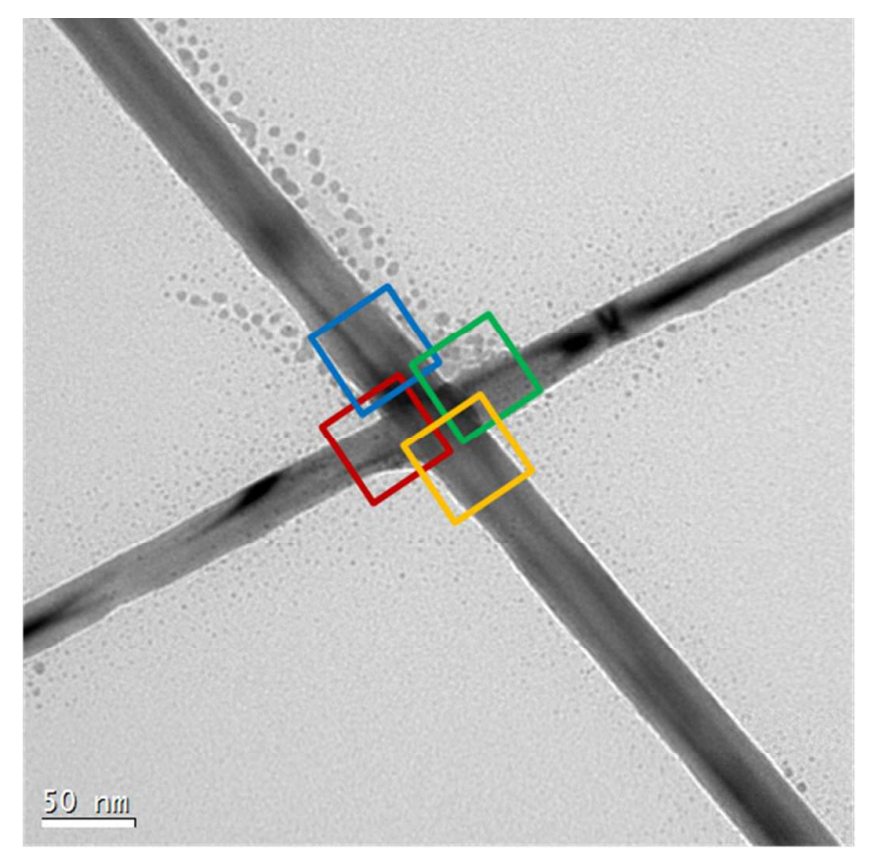

(d)
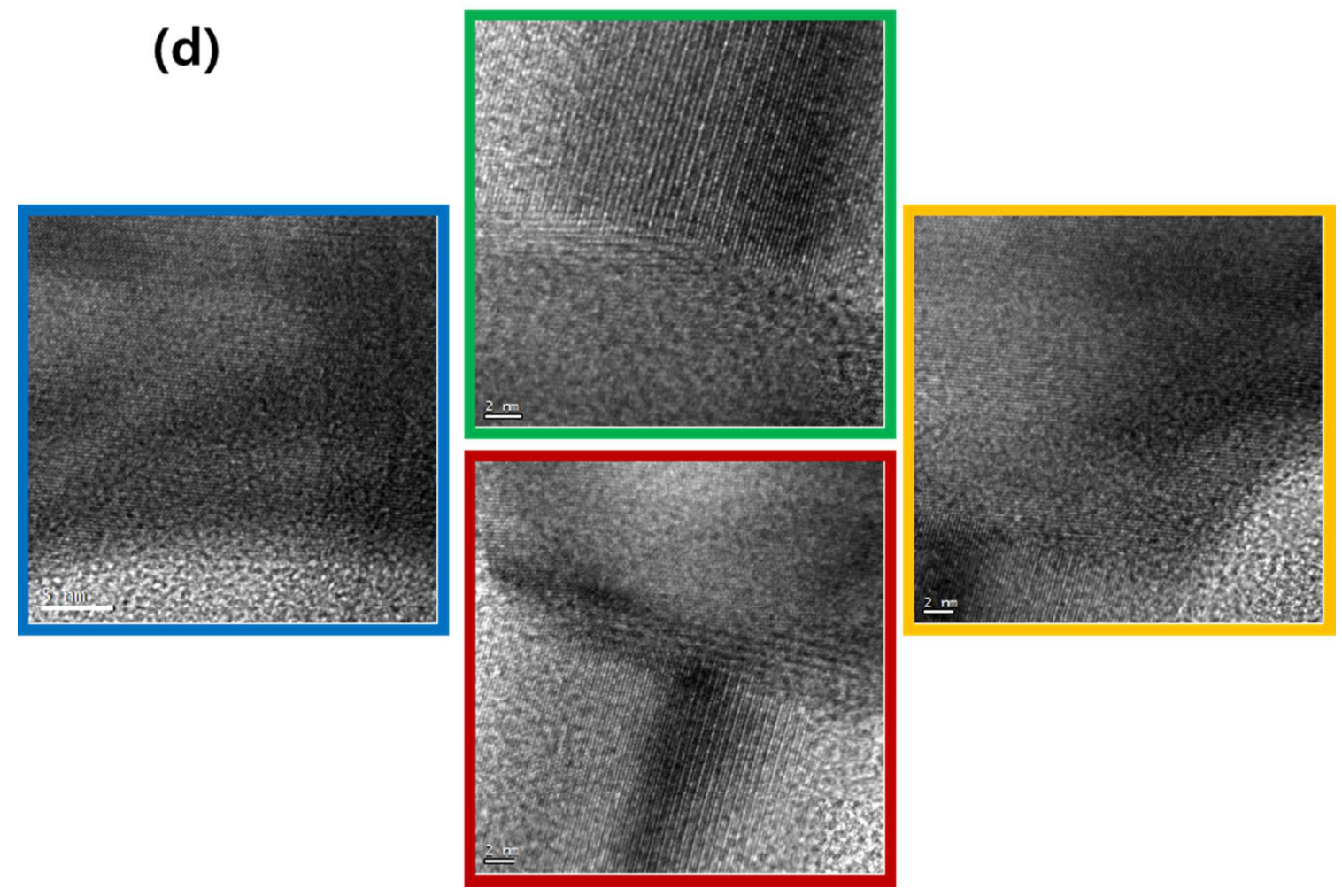

Figure S3. (continued) (d) Lattice-resolved HR-TEM images around the welded junction. The colored boxes in upper image (scale bar: $50 \mathrm{~nm}$ ) were magnified (scale bar: $2 \mathrm{~nm}$ ), and shows that each nanowire retains their original crystallinity after the chemical welding. In other words, the chemical welding is very localized process occurring at the junction only. 

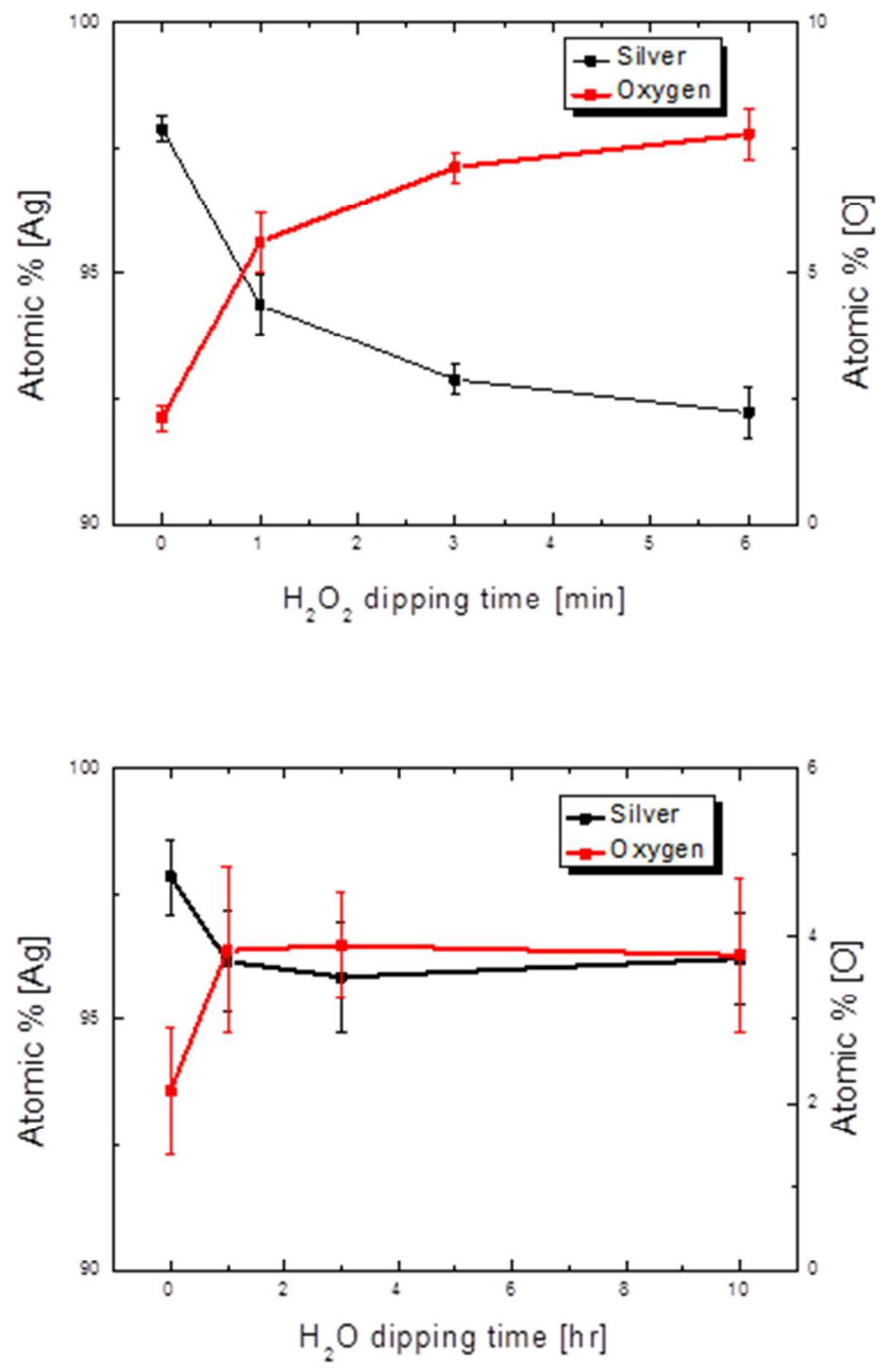

(e)

Figure S3. (continued) (e) Comparison of EDX spectra between $\mathrm{H}_{2} \mathrm{O}_{2}$-treated (top) and water-treated (bottom) Ag pellets. Both the dipping in $\mathrm{H}_{2} \mathrm{O}_{2}$ and in $\mathrm{H}_{2} \mathrm{O}$ shows slight increase in $\mathrm{O}$ signal, from $\sim 2 \%$ to $5 \sim 7 \%$. Considering the fact that silver oxide $\left(\operatorname{Ag}_{2} \mathrm{O}\right)$ is converted into $\mathrm{Ag}$ by $\mathrm{H}_{2} \mathrm{O}_{2}$, the increased $\mathrm{O}$ signal is probably due to the formation of hydrated form of $\mathrm{Ag}$ such as silver hydroxide $(\mathrm{AgOH})$. The silver hydroxide is known to be unstable and easily turn into $\mathrm{Ag}_{2} \mathrm{O}\left(2 \mathrm{AgOH} \rightarrow \mathrm{Ag}_{2} \mathrm{O}+\mathrm{H}_{2} \mathrm{O}\right)$, again which decomposes into $\mathrm{Ag}$ and $\mathrm{H}_{2} \mathrm{O}$ by $\mathrm{H}_{2} \mathrm{O}_{2}\left(\mathrm{Ag}_{2} \mathrm{O}+\mathrm{H}_{2} \mathrm{O}_{2} \rightarrow 2 \mathrm{Ag}+\mathrm{H}_{2} \mathrm{O}+\mathrm{O}_{2}\right)$. Therefore, we believe that there is no formation of surface oxide on chemically welded AgNWs network. 

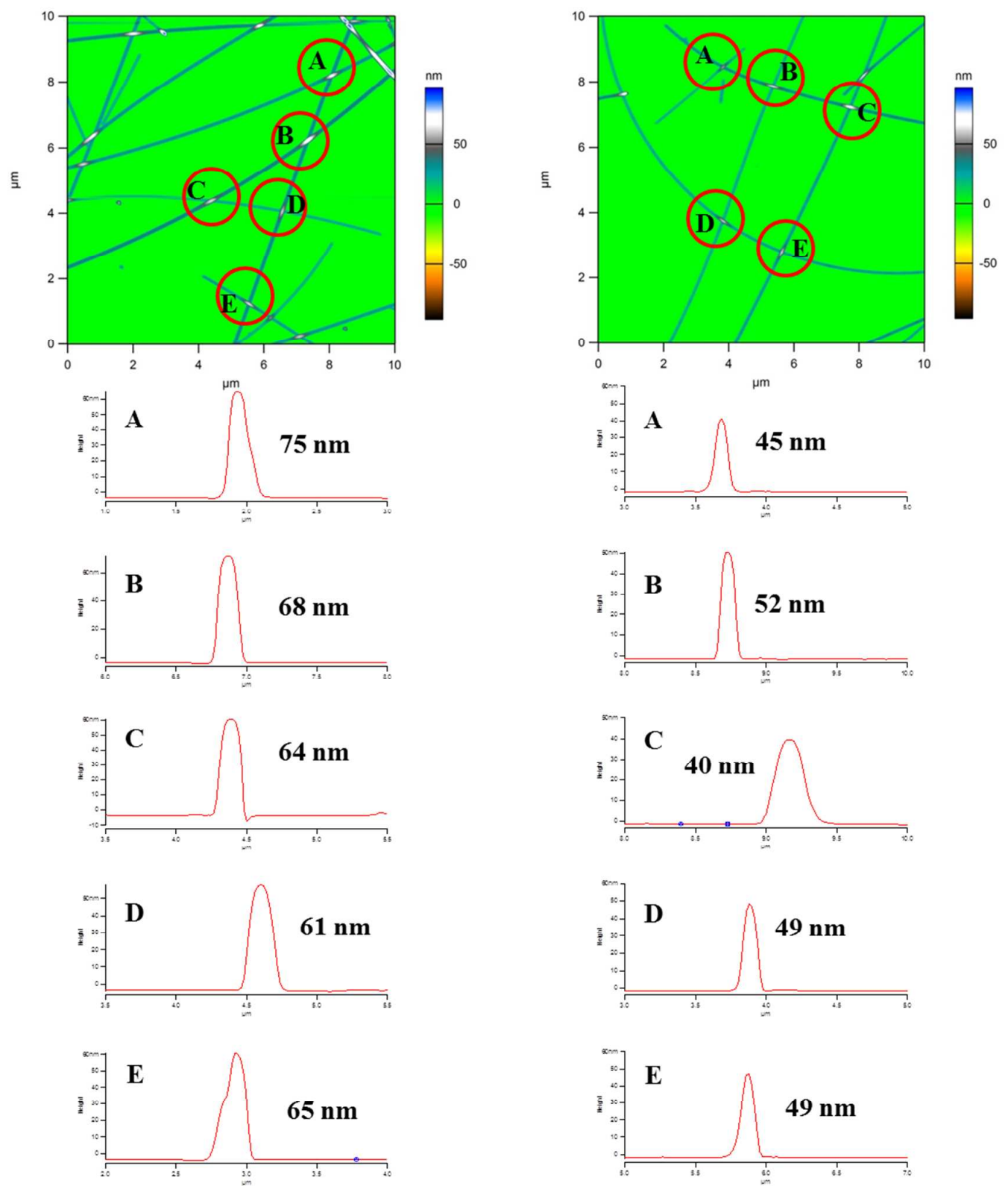

(a)

(b)

Figure S4. Representative section profiles of pristine vs. welded AgNWs by AFM. (a) Nonwelded sample, where the junction height is $>60 \mathrm{~nm}$, and (b) Chemically welded junction showing reduced junction height $(<50 \mathrm{~nm})$, respectively. 

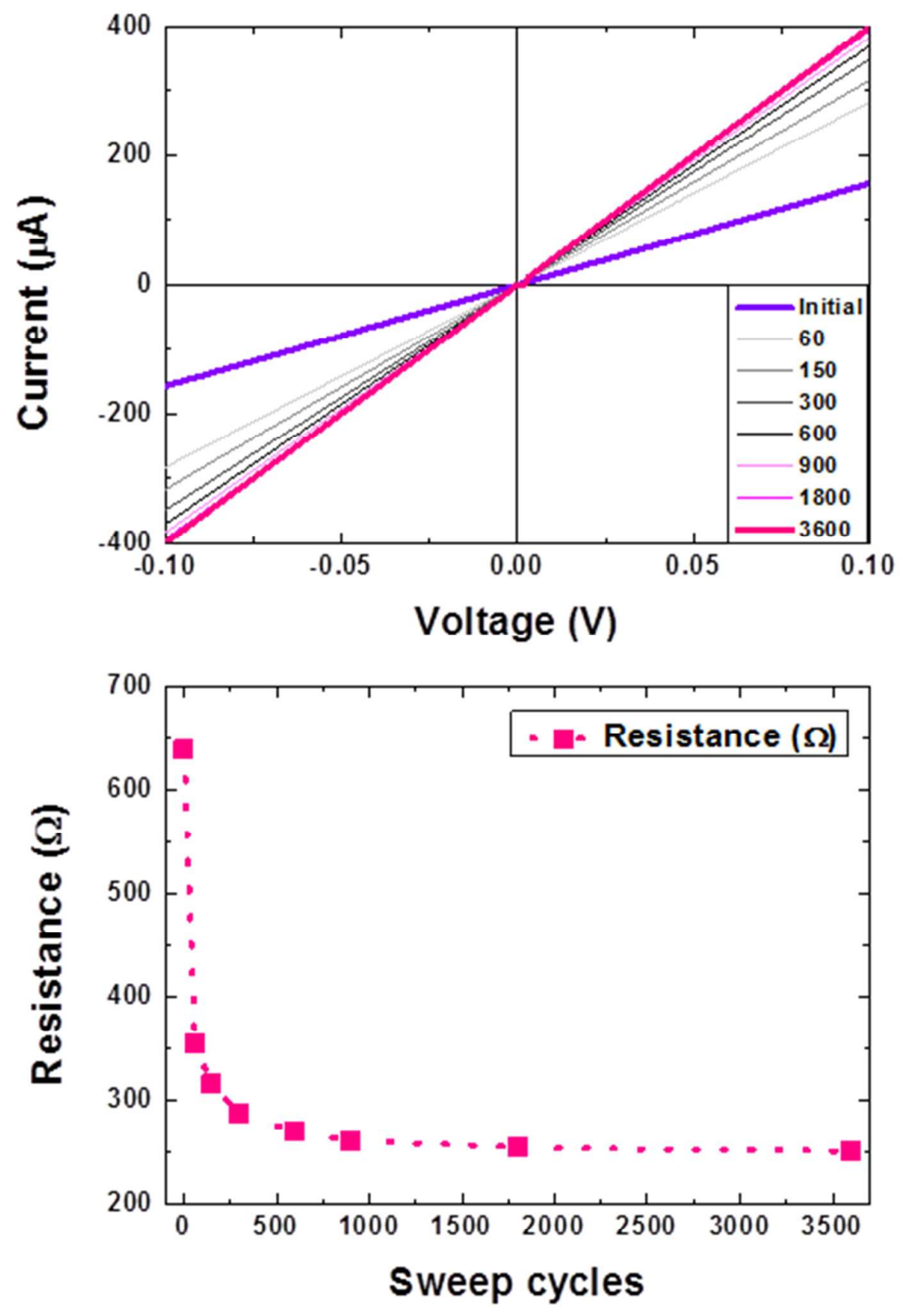

Figure S5. Resistance change by Joule heating. The AgNWs network on a glass substrate was swept repeatedly from $-0.1 \mathrm{~V}$ to $0.1 \mathrm{~V}$, which has led to resistance decrease due to thermal welding induced by Joule heating at junctions. The resistance saturated at $\sim 250 \mathrm{Ohm}$, which is $2 \sim 10$ times higher than that for chemically welded samples. Also, the Joule heating has led to asymptotic behavior in the resistance upon prolonged cycling, while the chemical welding yielded minimum resistance at certain exposure time and then increase again due to random chemical attack on Ag nanowires as shown in Fig. 2(a) of the Main Text. 


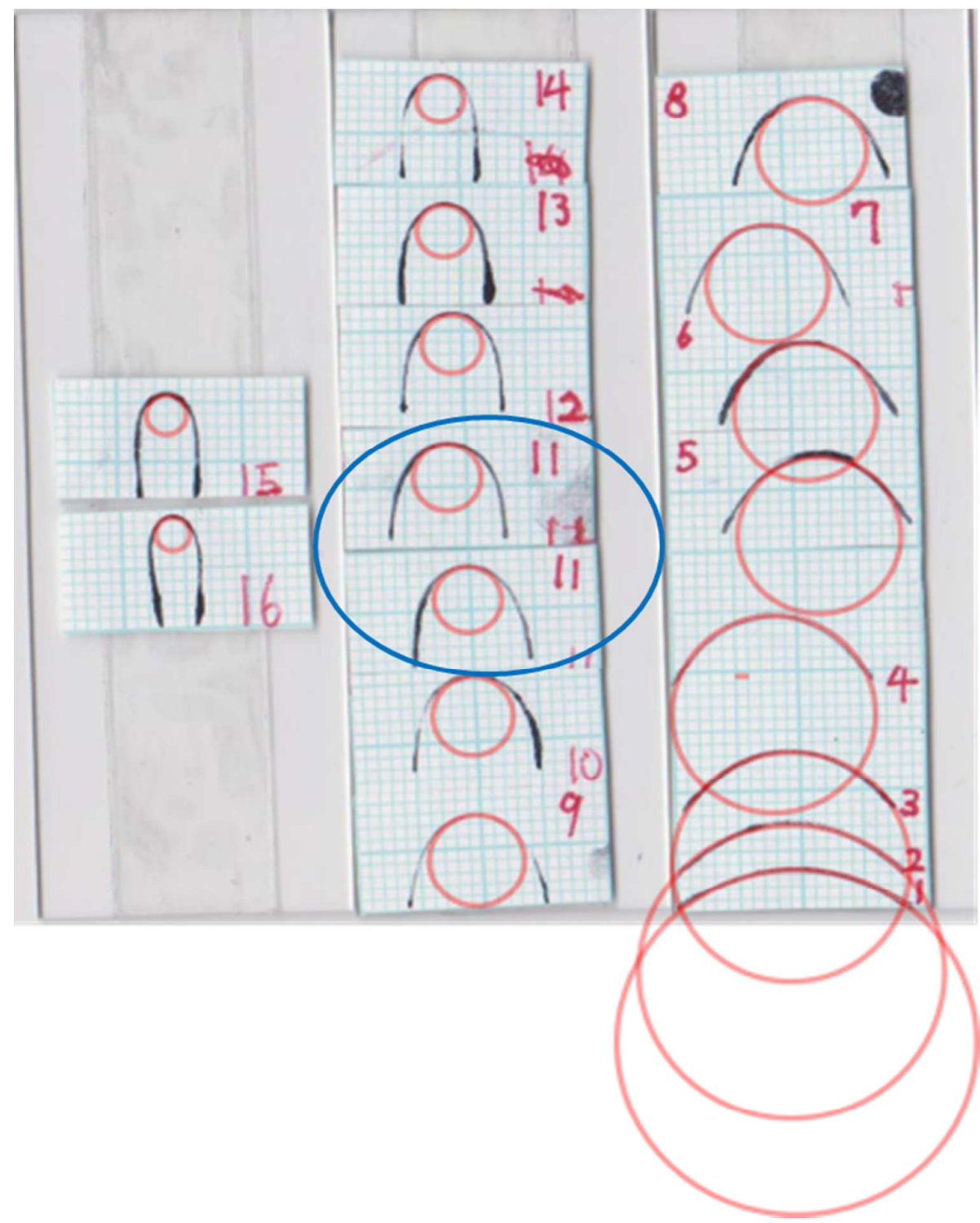

Figure S6. Bending test for the welded AgNWs network on PET substrate. While bent under a probe station for electrical measurements, the sample edge was inked and the bent contour was pressed against a grid paper. The bending radii (and thus strain) were measured by fitting circles onto the imaged contours, as shown above. Note here that the bent shape of sample starts to deviate significantly from the ideal cylindrical bending configuration as the bending curvature is increased. For these non-cylindrical bending cases, our method can give more accurate results on sample strain than any other calculations using formula. Note that we measured " 11 " two times by mistake, as encircled in blue color. 

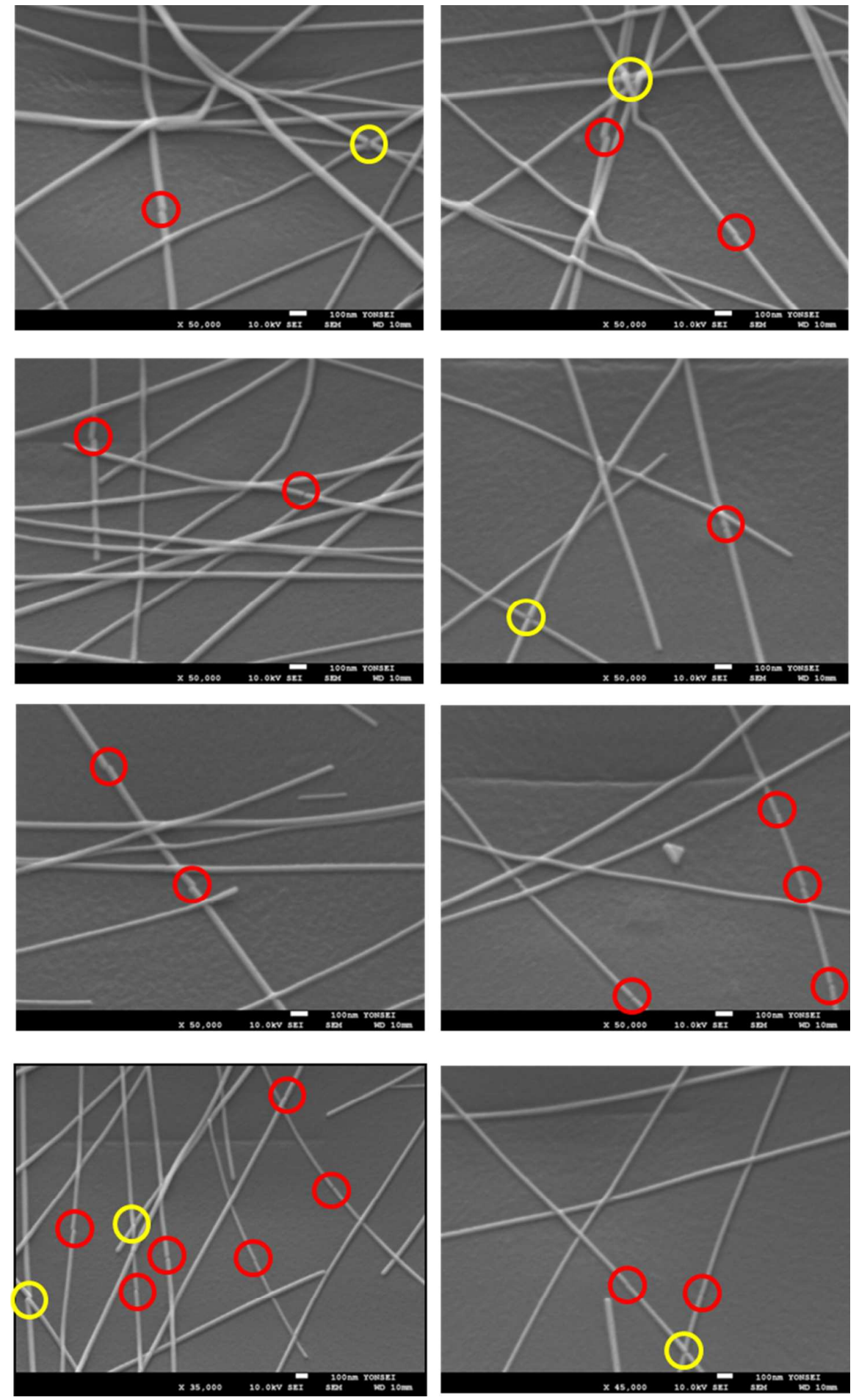

Figure S7. Fracture behavior of chemically welded AgNWs network. The AgNWs network on a PET substrate was chemically welded by exposure to $\mathrm{H}_{2} \mathrm{O}_{2}$ vapor for $20 \mathrm{~min}$ at RT, and then the sample was bent to $\sim 10 \%$ tensile strain. Yellow circles denote fracture at junctions, while the red ones indicate fractures on non-welded, single nanowire surface. 
(a)
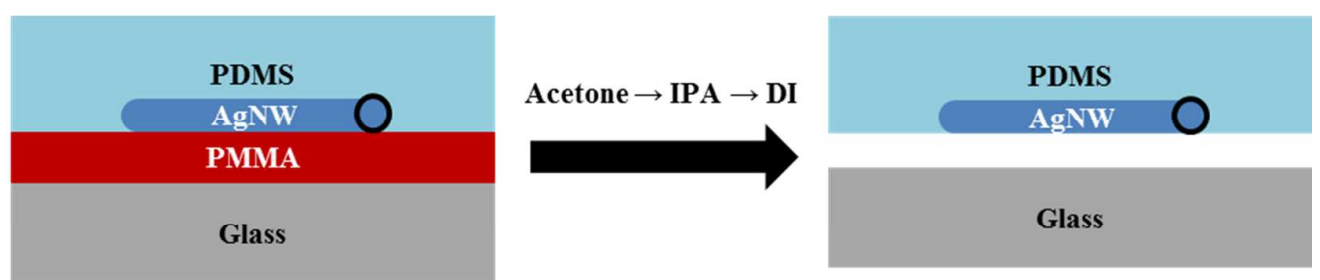

(b)
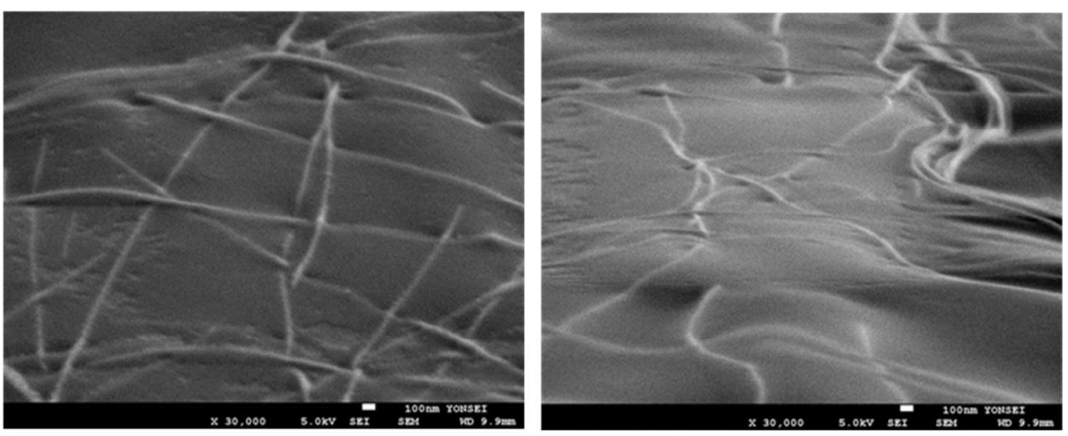

\section{Initial}

(c)
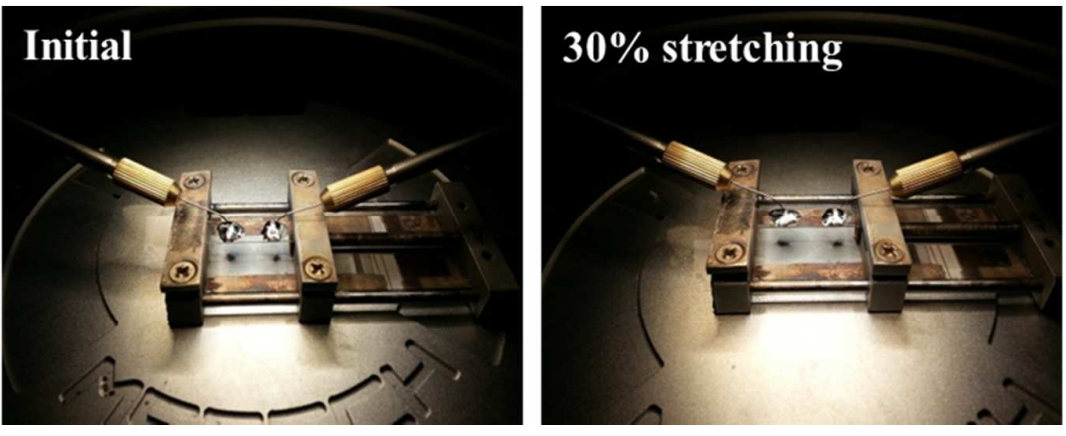

Figure S8. Chemically welded Ag nanowires network embedded into elastomeric PDMS substrate. (a) Schematic illustration of fabrication process. PMMA( $\sim 500 \mathrm{~nm})$ was used as a sacrificial layer. After spin-coat AgNWs on PMMA/glass, the network was chemically welded by $\mathrm{H}_{2} \mathrm{O}_{2}$ vapor exposure. Pouring and curing PDMS has led to partial embedding of the network into the elastomer. Dissolution of PMMA in acetone has yielded the final structure, that is, stretchable network of chemically welded and partially embedded AgNWs on PDMS, as shown in SEM images of (b). (c) Photographs showing electrical measurement under stretching. For the stretchable electrical contact, eutectic GaIn drops were used (shown as shiny bright spots on the photos) 

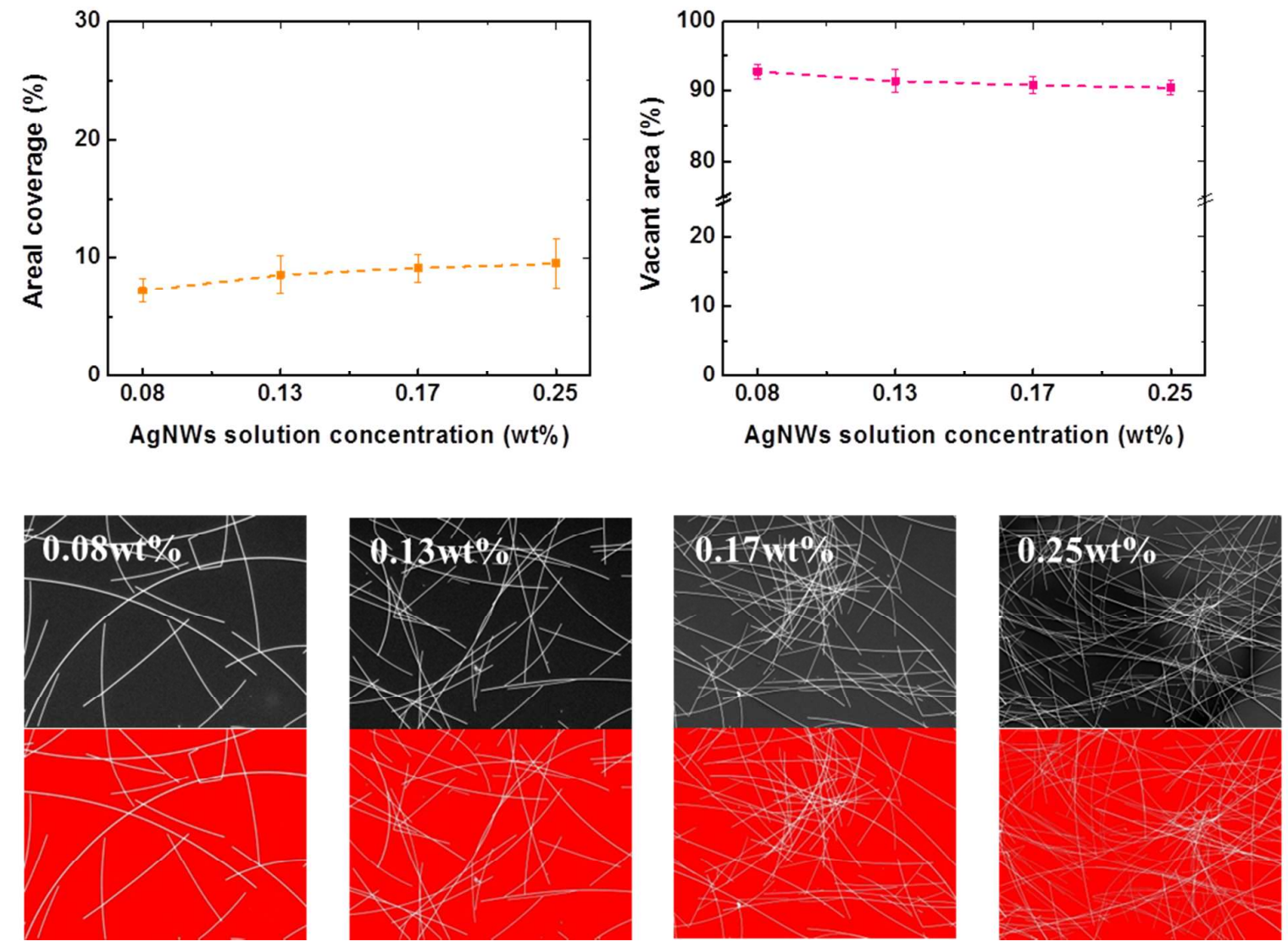

Figure S9. Areal coverage of AgNWs as a function of solution concentration. (Top) Areal coverage (left) and percentage of vacant area (right) on a substrate covered with $\mathrm{Ag}$ nanowires prepared from different solution concentration. (Middle) Plane-view SEM images, and (Bottom) Digitally processed images of the corresponding SEM images to count the number of pixels that are occupied by Ag nanowires. Though the number density changes a lot from sample to sample, the surface areal coverage by nanowires does not vary much as the solution concentration is increased from $0.08 \mathrm{wt} \%$ up to $0.25 \mathrm{wt} \%$. This is the reason why the optical transmittance of these samples is almost the same while the electrical resistance differs a lot from each other. 

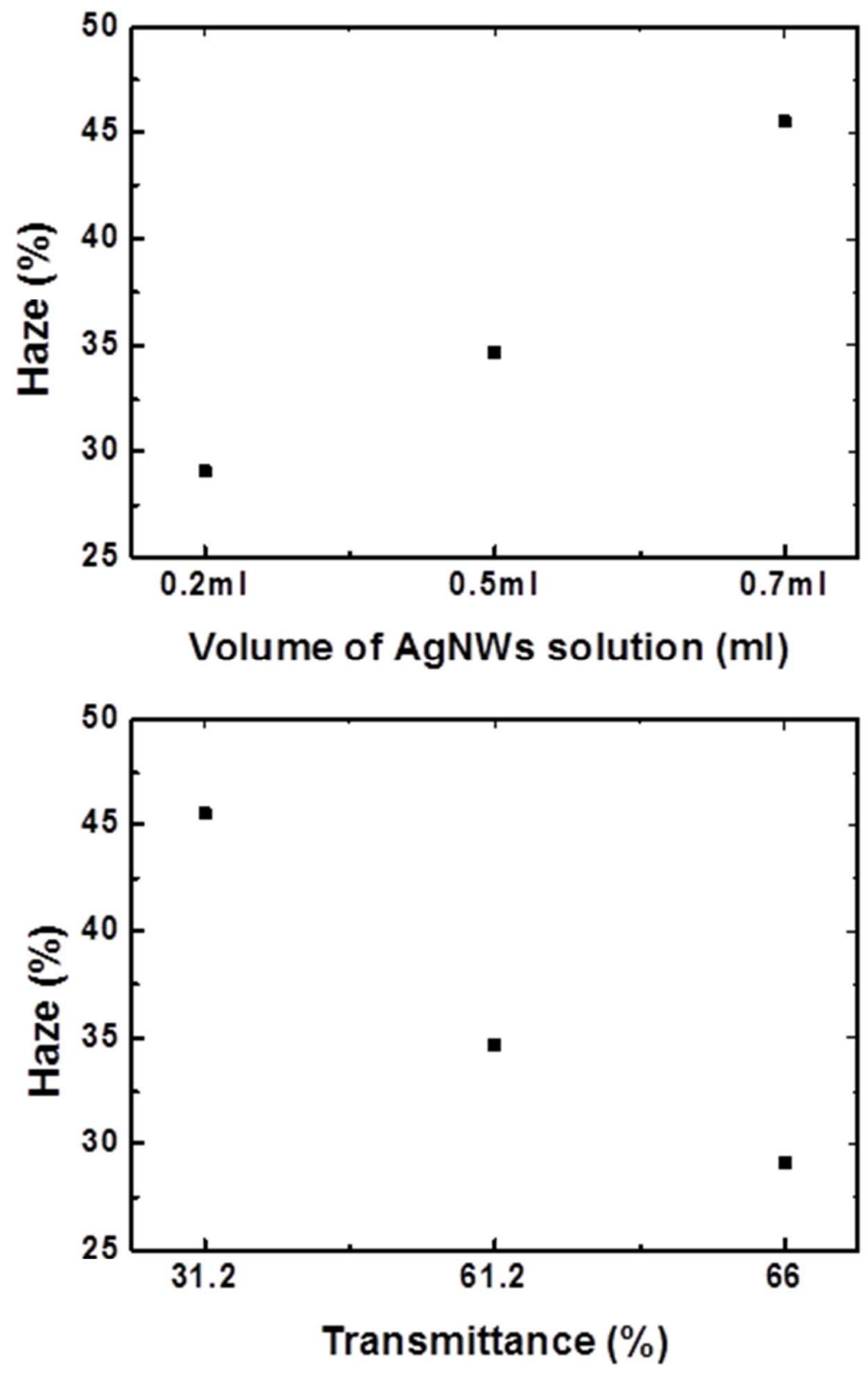

Figure S10. Optical haze of chemically welded AgNWs network on PDMS. (a) Optical haze of welded AgNWs on PDMS substrate as a function of solution volume sprayed on. The AgNWs solution used for the spraying was $0.13 \mathrm{wt} \%$. As the sprayed volume of solution is increased, the electrical resistance decreases as shown in Fig. 3c of the Main Text. This increase in conductance (and stretchability as well) accompanies increase (decrease) in haze (transparency), as shown in (b), where the haze was plotted against optical transparency. 


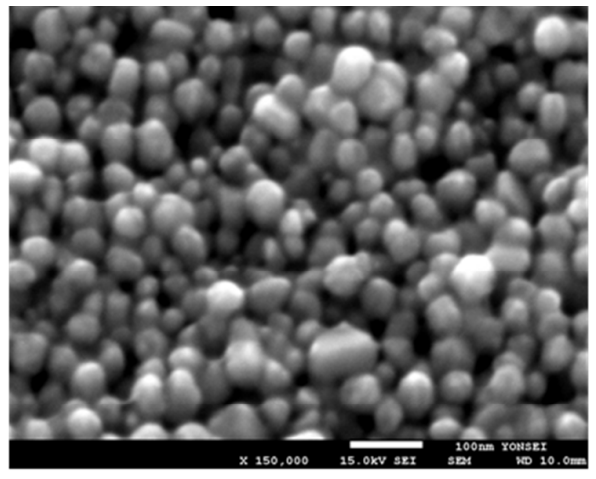

$0 \mathrm{~min}$.

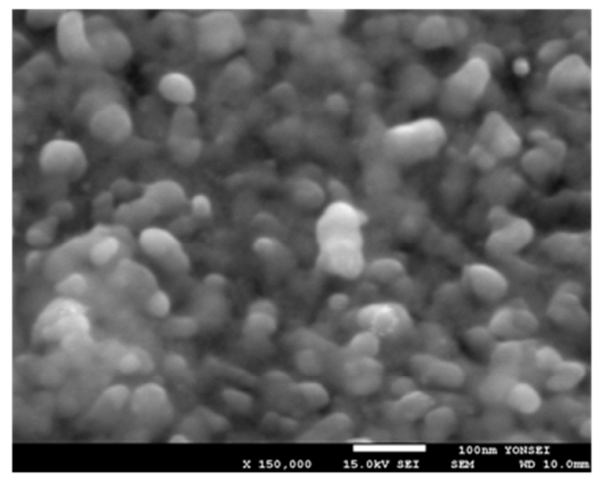

$60 \mathrm{~min}$.

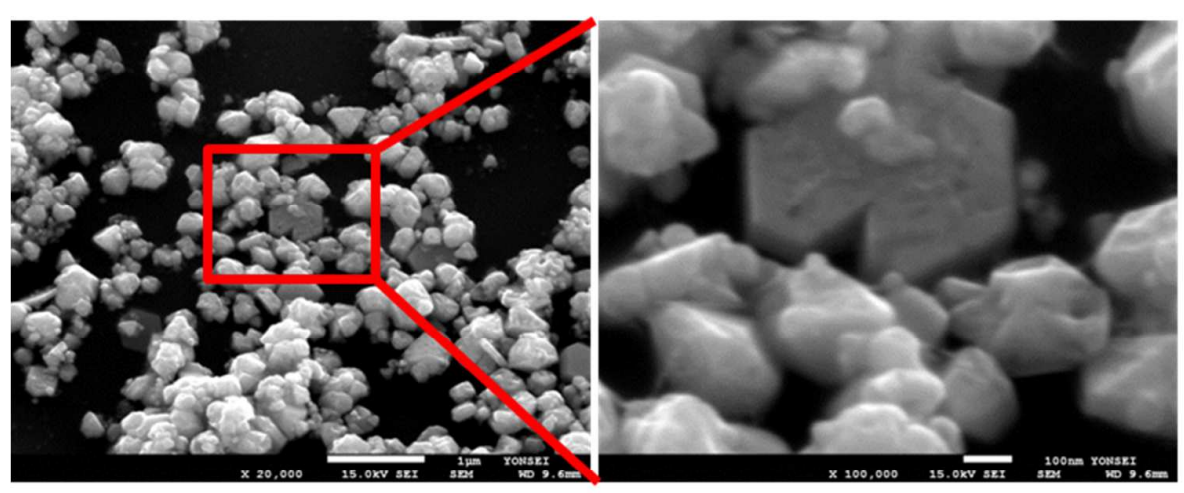

$12 \mathrm{hrs}$

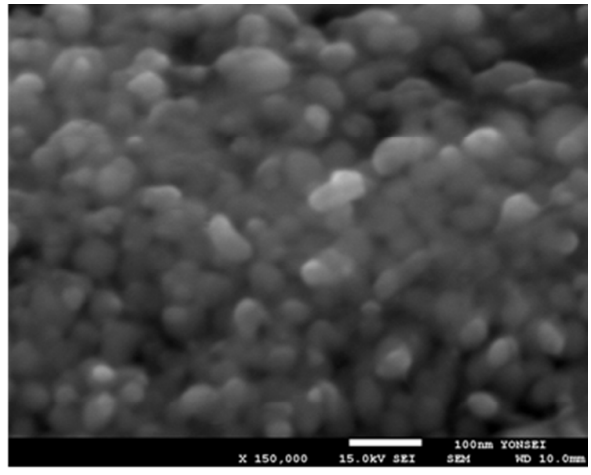

$20 \mathrm{~min}$.

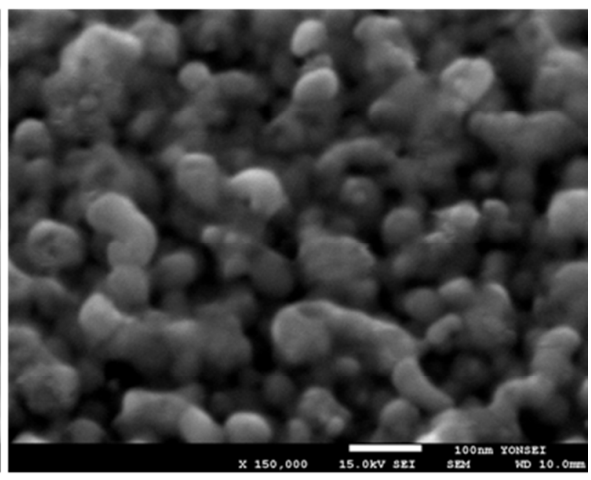

$120 \mathrm{~min}$.

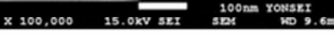

Figure S11. Morphology change of chemically sintered Ag nanoparticles on $\mathrm{Si}$, as a function of vapor exposure time. Prolonged exposure has led to discontinuity in the layer, leading to the increase in electrical resistance as shown in the bottom panel of Fig. 4(a) in the Main Text. 

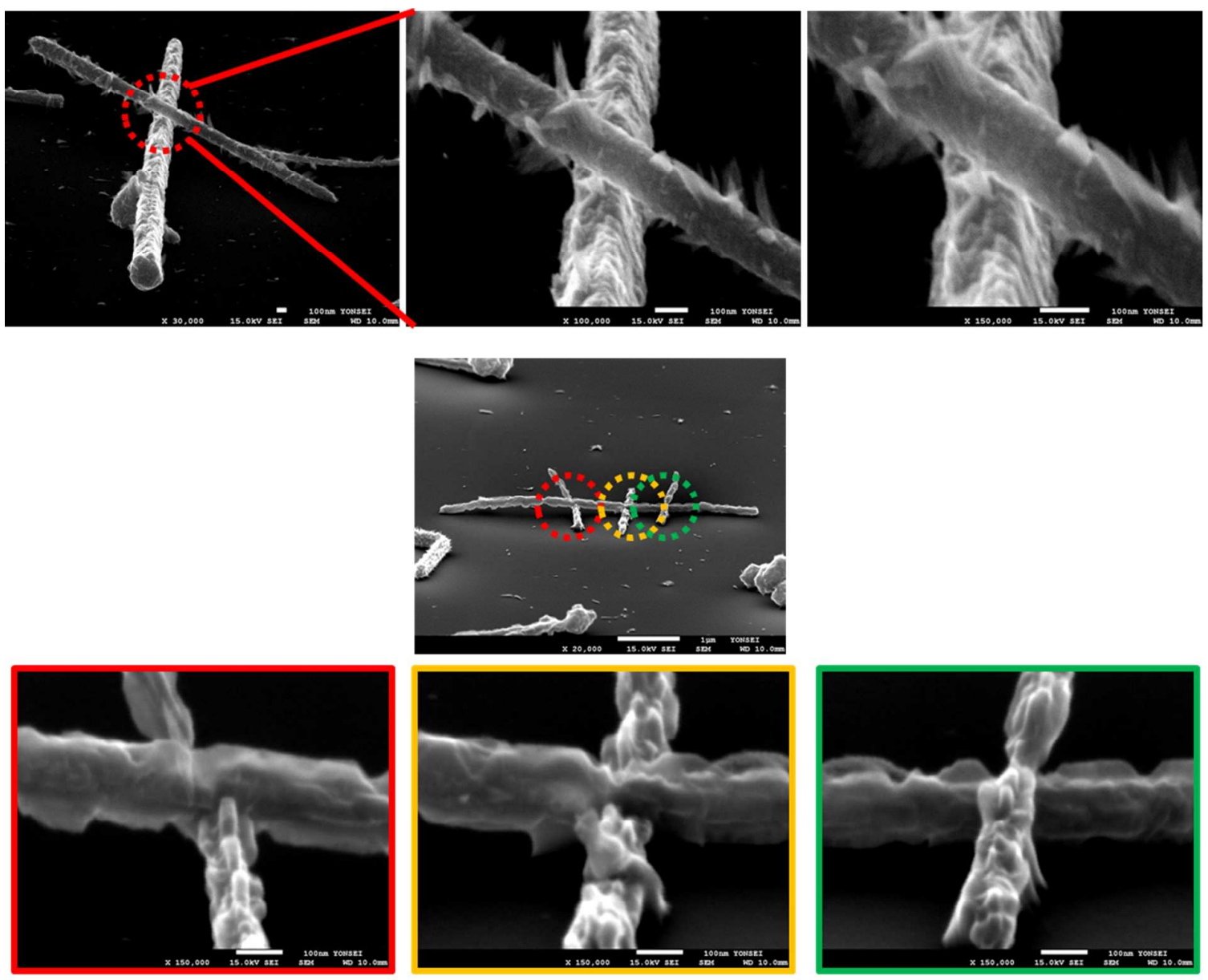

(a)

Figure S12. Chemical welding and sintering of $\mathrm{Cu}$ nanowires and Fe nanoparticles. (a) (Top) Pristine, non-welded $\mathrm{Cu}$ nanowires on a $\mathrm{Si}$ substrate. (Bottom) Chemically welded $\mathrm{Cu}$ nanowires by $\mathrm{H}_{2} \mathrm{O}_{2}$ vapor exposure for $10 \mathrm{~min}$. Note here that the $\mathrm{Cu}$ nanowires used in this work are not in good quality, thus the change in electrical resistance upon chemical welding could not be measured due to rather short length of those $\mathrm{Cu}$ nanowires. 

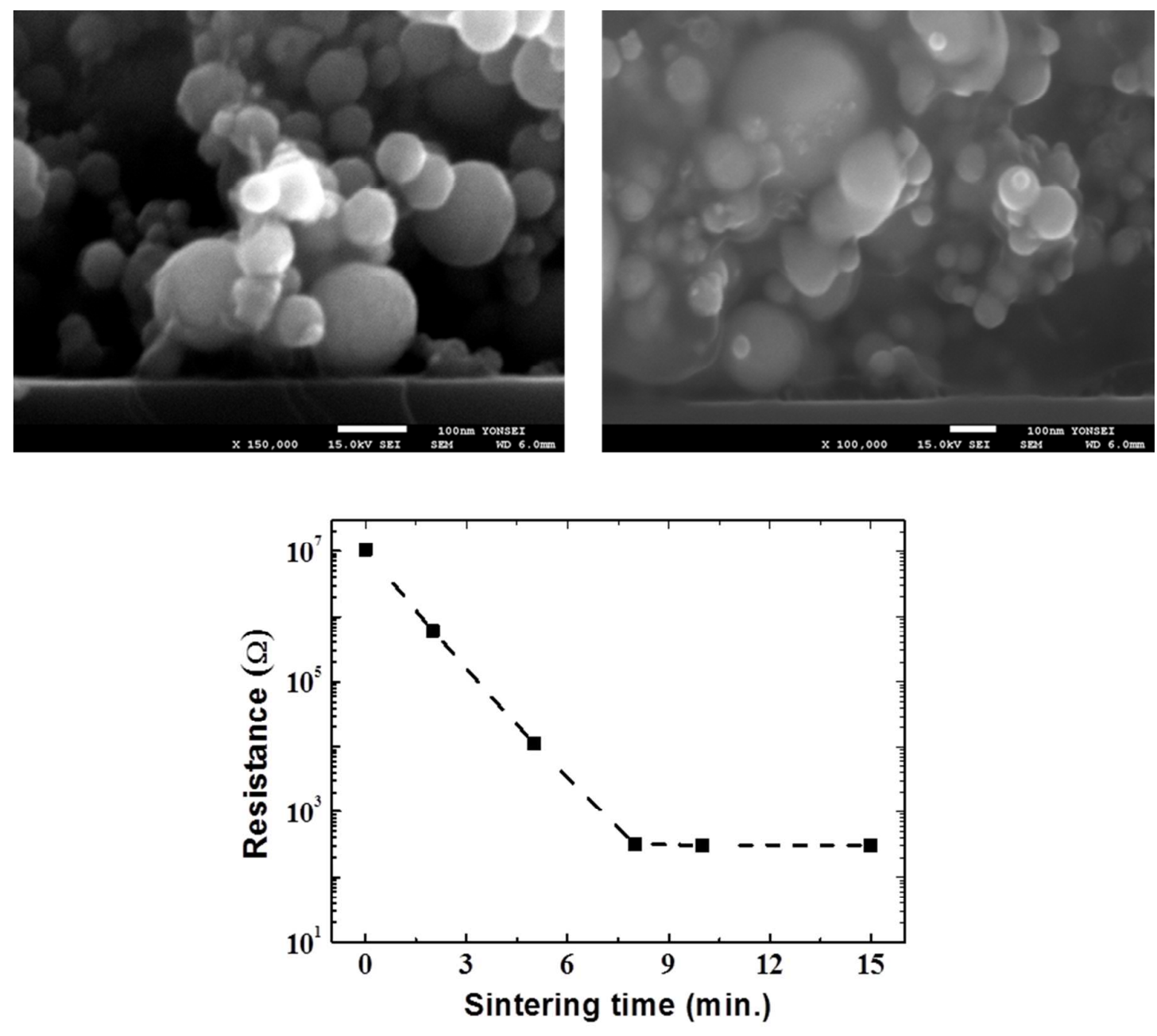

(b)

Figure S12. (Continued) (b) Pristine, non-welded Fe nanoparticles layer (left), after chemical sintering (middle), and change in electrical resistance as a function of sintering time (right), respectively. There is $\sim 5$ orders of magnitude reduction in resistance upon the chemical sintering, which is quite similar to other metals shown in Fig. 4 in the Main Text. 

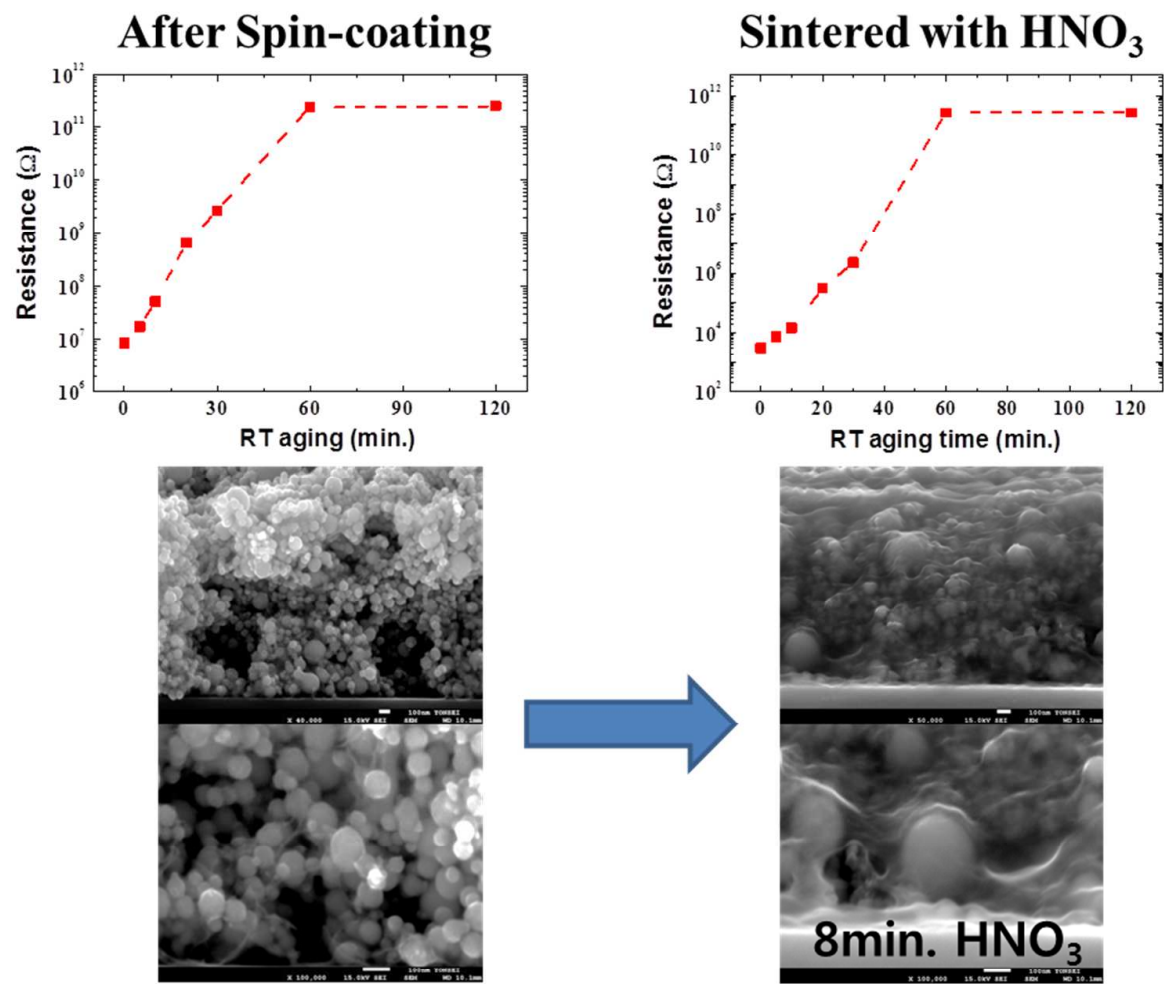

\section{Sintered with $\mathrm{H}_{2} \mathrm{O}_{2}$}

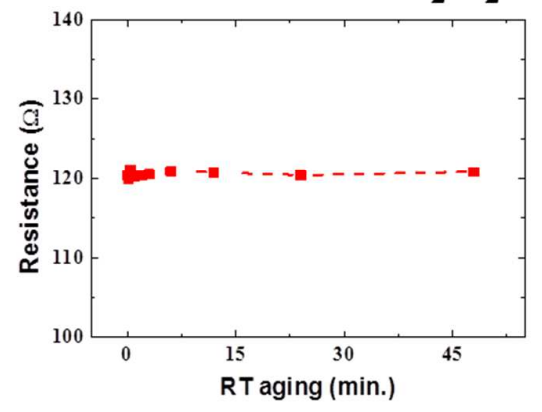

Figure S13. Chemical sintering of metal (Co) nanoparticles using chemical other than $\mathrm{H}_{2} \mathrm{O}_{2}$. (Top left) Right after the spin coating, where gradual surface oxidation has led to increase in the resistance. (Top right) Chemical sintering using $\mathrm{HNO}_{3}$ vapor: the resistance dropped down to $\sim 1000 \mathrm{Ohm}$ right after the chemical vapor treatment. The resistance, however, has increased again up to $10^{12} \mathrm{Ohm}$ upon drying. The resistance increase is due to nonconductive metal salt $\left(\mathrm{CoNO}_{3}\right.$ in the case of $\left.\mathrm{Co}\right)$ formed upon drying. Note here that the sintered morphology by $\mathrm{HNO}_{3}$ is quite similar to that by $\mathrm{H}_{2} \mathrm{O}_{2}$ (Fig. 4(d) in Main Text). (Bottom) Chemical sintering using $\mathrm{H}_{2} \mathrm{O}_{2}$ vapor, where no change in resistance occurs even after a prolonged exposure to room ambient. 

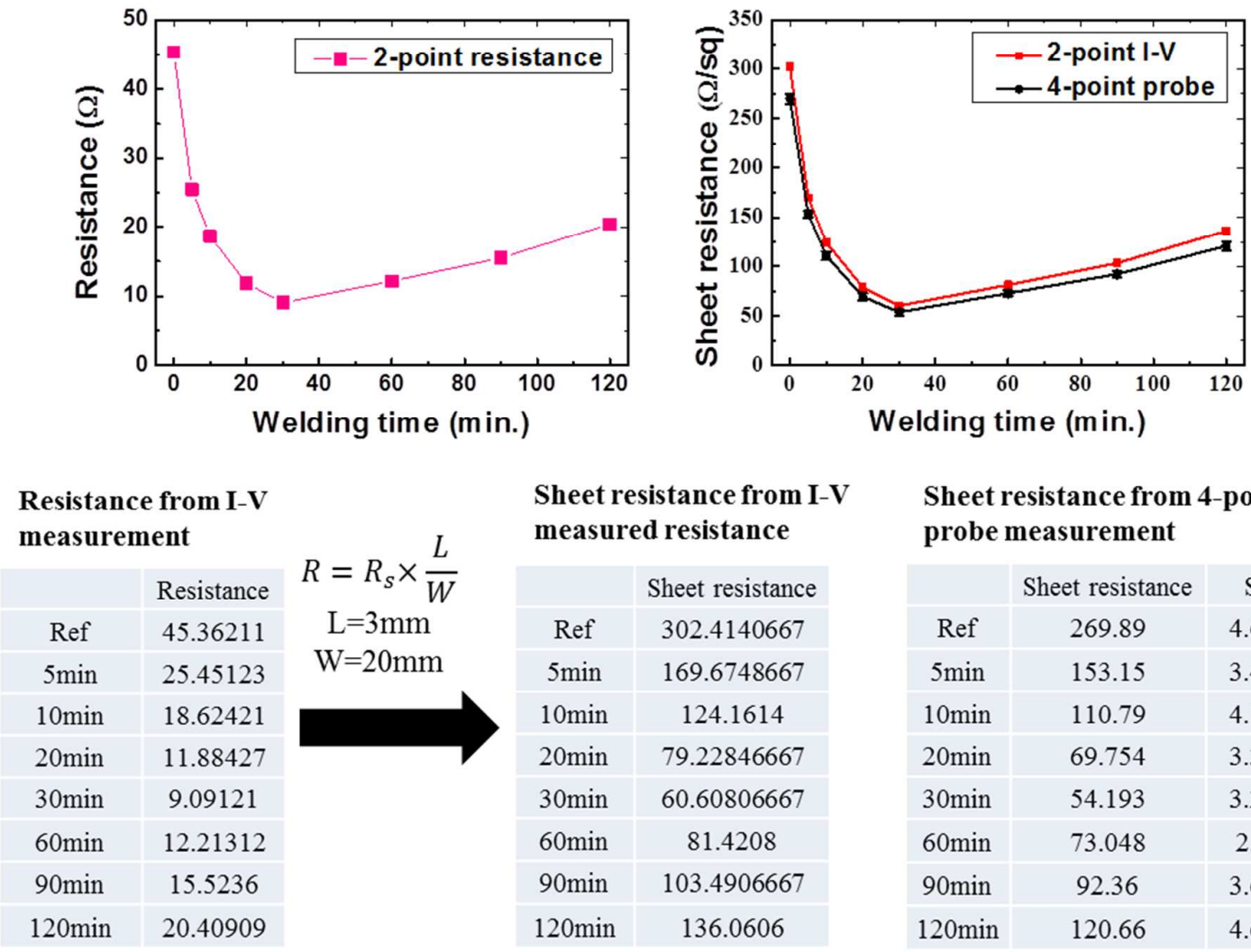

\begin{tabular}{|c|c|}
\hline & Sheet resistance \\
\hline Ref & 302.4140667 \\
\hline $5 \mathrm{~min}$ & 169.6748667 \\
\hline $10 \mathrm{~min}$ & 124.1614 \\
\hline $20 \mathrm{~min}$ & 79.22846667 \\
\hline $30 \mathrm{~min}$ & 60.60806667 \\
\hline $60 \mathrm{~min}$ & 81.4208 \\
\hline $90 \mathrm{~min}$ & 103.4906667 \\
\hline $120 \mathrm{~min}$ & 136.0606 \\
\hline
\end{tabular}

\begin{tabular}{|c|c|c|}
\hline \multicolumn{3}{|c|}{$\begin{array}{l}\text { Sheet resistance from } 4 \text {-point } \\
\text { probe measurement }\end{array}$} \\
\hline & Sheet resistance & Stdev \\
\hline Ref & 269.89 & 4.66082 \\
\hline $5 \mathrm{~min}$ & 153.15 & 3.43099 \\
\hline $10 \mathrm{~min}$ & 110.79 & 4.19535 \\
\hline $20 \mathrm{~min}$ & 69.754 & 3.35107 \\
\hline $30 \mathrm{~min}$ & 54.193 & 3.24428 \\
\hline $60 \mathrm{~min}$ & 73.048 & 2.9093 \\
\hline $90 \mathrm{~min}$ & 92.36 & 3.67641 \\
\hline $120 \mathrm{~min}$ & 120.66 & 4.60415 \\
\hline
\end{tabular}

Figure S14. Resistance vs. sheet resistance. It is impossible to measure the sheet resistance (by 4-point probe) during bending or stretching, while simple 2-point I-V measurements are possible. The measured resistance values (by 2-point I-V), shown in left plot, were converted into sheet restance using conversion formulae and geometric factors (electrode width, and distance between electrodes) and plotted (red points, right graph). Also plotted are sheet resistance data measured directly from 4-point probe technique (black points in the right graph). The sheet resistance extracted from the simple 2-point measurement is only $\sim 10 \%$ larger than that from direct 4-point measurements, which gives quite good (and conservative) estimates for bending/stretching test. 